\title{
KELAYAKAN FINANSIAL DAN STRATEGI PENGEMBANGAN AGROINDUSTRI SABUT KELAPA CV SUMBER SARI DI DESA LEMBENGAN KECAMATAN LEDOKOMBO KABUPATEN JEMBER FINANCIAL FEASIBILITY AND DEVELOPMENT STRATEGY OF COCONUT FIBER AGROINDUSTRY CV SUMBER SARI IN LEMBENGAN VILLAGE LEDOKOMBO DISTRICT JEMBER REGENCY
}

\author{
Fandy Adry Willy Putranto ${ }^{1}$ dan Ebban Bagus Kuntadi ${ }^{2}$ \\ ${ }^{1}$ Mahasiswa Program Studi Agribisnis Fakultas Pertanian Universitas Jember \\ ${ }^{2}$ Staf Pengajar Program Studi Agribisnis Fakultas Pertanian Universitas Jember \\ e-mail: fandywilly.fw@gmail.com
}

\begin{abstract}
Coconut coir is the outermost part of the coconut which wraps the coconut shell. Agro-industry in Jember Regency which processes coconut fiber is located in Lembengan Village, Ledokombo District, Jember Regency. Production activities require the use of planned costs in order to get optimal profits with the investments that have been made, so that the flow of money or cash that is in the CV Sumber Sari agro-industry goes well and can avoid risks that result in income for the development of agroindustry.This study aims to determine: (1) the feasibility analysis of CV Sumber Sari coconut coir agroindustry in Lembengan Village, Ledokombo District, Jember Regency; (2)Sensitivity analysis of parameter changes that occur. Determination of the study area using purposive method, at the CV Sumber Sari agroindustry in Lembengan Village, Ledokombo District. The method of sampling is done intentionally or purposive sampling using certain criteria. The data used are primary and secondary data by using data collection methods in the form of observation, interviews, and documentation. The data were then analyzed using feasibility criteria analysis and sensitivity analysis. The results showed that 1) Coconut fiber Agroindustry CV Sumber Sari, Jember Regency is worth the effort. NPV value of Rp. 6.794.149.777. PI value or Net B / C of 6,7041. IRR value of 66,32\%. PP value of 1 year 11 months 25 days (Bank Indonesia interest rate 6.50\%). 2) Coconut coir agroindustry CV Sumber Sari, Jember Regency is not sensitive to changes in the variable cost of coconut fiber raw material increases by $100 \%$ and decreases in selling prices of products by $15 \%$ so that it is still viable for business.
\end{abstract}

Keywords : Coconut coir, agroindustry, feasibility citeria, sensitivity.

\begin{abstract}
ABSTRAK
Sabut kelapa merupakan bagian terluar buah kelapa yang membungkus tempurung kelapa. Agroindustri di Kabupaten Jember yang mengolah sabut kelapa terletak di Desa Lembengan Kecamatan Ledokombo Kabupaten Jember. Kegiatan produksi memerlukan penggunaan biaya yang terencana agar mendapatkan keuntungan yang optimal dengan investasi yang telah dilakukan, sehingga aliran uang atau kas yang ada pada agroindustri CV Sumber Sari berjalan dengan baik dan dapat menghindari resiko yang berakibat pada pendapatan untuk pengembangan agroindustri. Penelitian ini bertujuan untuk mengetahui: (1) analisa kelayakan agroindustri sabut kelapa CV Sumber Sari di Desa Lembengan Kecamatan Ledokombo, (2) analisis sensitivitas terhadap perubahan parameter yang terjadi. Penentuan daerah penelitian menggunakan purposive method yaitu pada agroindustri CV Sumber Sari di Desa Lembengan Kecamatan Ledokombo. Metode pengambilan contoh dilakukan secara sengaja atau purposive sampling menggunakan kriteria tertentu. Data yang digunakan merupakan data primer dan sekunder dengan menggunakan metode pengumpulan data berupa observasi, interview (wawancara), dan dokumentasi. Data tersebut kemudian dianalisis menggunakan analisis kriteria kelayakan dan analisis sensitivitas. Hasil penelitian menunjukkan bahwa 1) Agroindustri sabut kelapa CV Sumber Sari Kabupaten Jember layak untuk di usahakan. Nilai NPV
\end{abstract}


sebesar Rp 6.794.149.777,-. Nilai PI atau Net B/C sebesar 6,7041. Nilai IRR sebesar 66,32\%. Nilai PP sebesar 1 tahun 11 bulan 25 hari (tingkat suku bunga Bank Indonesia 6,50\%). 2) Agroindustri sabut kelapa CV Sumber Sari Kabupaten Jember tidak sensitif terhadap perubahan kenaikan biaya variabel bahan baku sabut kelapa sebesar $100 \%$ dan penurunan harga jual produk sebesar $15 \%$ sehingga tetap layak untuk di usahakan.

Kata Kunci: Sabut Kelapa, Agroindustri, Kriteria Kelayakan, sensitivitas

\section{PENDAHULUAN}

Agroindustri adalah industri yang menghasilkan produk-produk yang komponen utamanya berasal dari hewan dan tumbuhan. Agroindustri menjadi pilihan untuk dikembangkan dengan konsep pemberdayaan petani kecil. Kebijakan yang telah ditetapkan tersebut diharapkan dapat membuat semakin banyak bertumbuh kembangnya usaha-usaha berbasis agroindustri berbasis pedesaan yang dapat mentransformasikan (merubah melalui sistem kelembagaan yang mapan) potensi keunggulan komparatif (comparative advantage) menjadi keunggulan kompetitif (competitive advantage), yaitu dengan melalui penciptaan nilai tambah (added value) produk dan penciptaan peluang pasar, terutama pasar luar negeri (ekspor) selain pasar domestik. Konsep kebijakan tersebut diharapkan dapat menumbuhkan sektor pertanian sehingga mampu menjadi sumber pertumbuhan bagi perekonomian nasional Indonesia khusunya dalam hal pencapaian sasaran: mampu menyediakan pangan dengan berbagai macam olahan, sebagai salah satu wahana pemerataan pembangunan untuk mengatasi kesenjangan pendapatan, menjadi pasar nagi hasil pertanian, menhasilkan devisa, menyediakan lapangan pekerjaan, peningkatan pendapatan nasional, mempertahankan kelestarian sumberdaya (Sukardi, 2011).

Kebijakan menyeluruh dalam pengembangan agroindustri, yang mempertimbangkan aspek pertumbuhan, pemerataan dan keadilan serta berkelanjutan dalam porsi seimbang masih diperlukan. Kebijakan umum tersebut harus ditindaklanjuti dengan kebijakan khusus yang mengatur masalahmasalah spesifik dengan melibatkan pelaku agroindustri dari tingkat konseptual sampai operasional (Syarief, 1992). Agroindustri di Kabupaten Jember yang mengolah sabut kelapa tersebut terletak di Desa Lembengan Kecamatan Ledokombo Kabupaten Jember. Sabut kelapa yang merupakan sisa dari pengupasan buah kelapa juga dapat diolah kembali menjadi beberapa produk olahan yaitu dari menjadi serat (cocofiber) dan cocopeat. Serat sabut kelapa dapat diolah kembali menjadi produk berkaret dan geotextile. Cocopeat dapat digunakan sebagai substitusi gambut alam untuk industri bunga dan pelapis lapangan golf (Mahmud \& Yulius, 2005). Cocopeat merupakan salah satu media tumbuh yang dihasilkan dari proses penghancuran sabut kelapa, proses penghancuran sabut dihasilkan serat atau fiber, serta sebuk halus atau cocopeat. Kelebihan cocopeat sebagai media tanam dikarenakan karakteristiknya yang mampu mengikat dan menyimpan air dengan kuat, serta mengandung unsur-unsur hara esensial, seperti kalsium, magnesium, kalium, natrium, dan fosfor (Ramadhan dkk, 2018)

Agroindustri CV Sumber Sari merupakan satu-satunya agroindustri yang mampu berproduksi secara berkelanjutan dan mampu bertahan sampai saat ini di Kabupaten Jember dengan nama CV Sumber Sari. Agroindustri CV Sumber Sari telah melakukan investasi mesin pengolahan sabut kelapa 1 unit dan mesin press 1 unit sebesar Rp. 300.000 .000 untuk dapat melakukan produksi secara optimal dan memenuhi permintaan konsumen yang semakin meningkat. Kegiatan produksi tersebut memerlukan penggunaan biaya yang terencana agar mendapatkan keuntungan yang optimal dengan investasi yang telah dilakukan, sehingga aliran uang atau kas yang ada pada agroindustri CV Sumber Sari berjalan dengan baik dan dapat menghindari resiko yang berakibat pada pendapatan. Penggunaan biaya yang terencana tersebut utamanya terkait dengan biaya yang dikeluarkan untuk bahan baku utama yaitu sabut kelapa.

Biaya bahan baku utama sabut kelapa merupakan salah satu penggunaan biaya yang dapat mempengaruhi aliran uang atau kas pada agroindustri CV Sumber Sari. Biaya bahan baku utama sabut kelapa dapat berubah sesuai dengan ketersediaan bahan baku yang ada pada supplier, apabila bahan baku utama sabut kelapa semakin berkurang maka akan mempengaruhi harga sabut kelapa tersebut. Selain harga bahan baku utama, faktor lain yang dapat mempengaruhi aliran uang atau kas agroindustri CV Sumber Sari adalah harga output dari produksi pengolahan sabut kelapa. Perubahan 
harga output pengolahan sabut kelapa juga dapat mempengaruhi aliran uang atau kas agroindustri CV Sumber sari dari jumlah pendapatan yang akan diterima. Perubahan harga output juga dipengaruhi oleh bargaining power yang ada pada pembeli. Berdasarkan hasil dan kondisi yang terjadi dapat dikaji mengenai kelayakan agroindustri pengolahan sabut kelapa secara finansial dan analisis sensitivitas apabila terjadi perubahan harga pada faktor produksi baik input maupun output yang ada pada agroindustri CV Sumber Sari di Desa Lembengan Kecamatan Ledokombo Kabupaten Jember. Berdasarkan permasalahan yang ada tersebut dapat dirumuskan beberapa rumusan masalah yaitu: (1) Bagaimana kelayakan secara finansial dari agroindustri pengolahan sabut kelapa CV Sumber Sari di Desa Lembengan Kecamatan Ledokombo Kabupaten Jember; (2) Bagaimana sensitivitas dari agroindustri pengolahan sabut kelapa CV Sumber Sari di Desa Lembengan Kecamatan Ledokombo Kabupaten Jember. Penelitian ini bertujuan untuk mengetahui: (1) analisa kelayakan agroindustri sabut kelapa CV Sumber Sari di Desa Lembengan Kecamatan Ledokombo, (2) analisis sensitivitas terhadap perubahan parameter yang terjadi.

\section{METODE PENELITIAN}

Penelitian ini dilakukan di Desa Lembengan Kecamatan Ledokombo Kabupaten Jember. Menurut Sugiyono (2014), metode purposive merupakan suatu teknik penentuan lokasi penelitian secara sengaja berdasarkan atas pertimbangan-pertimbangan tertentu. Lokasi yang dipilih sebagai obyek penelitian adalah karena terdapat agroindustri yang mengusahakan atau mengolah bahan baku sabut kelapa CV Sumber Sari dan satu-satunya di Kabupaten Jember. Waktu penelitian yang dilakukan yaitu dimulai pada tanggal 01 Maret 2019 sampai dengan 15 April 2019 dengan analisis waktu penelitian yang dilakukan pada agroindustri CV Sumber Sari yaitu selama 8 tahun (mulai tahun 2010 sampai tahun 2018).

Metode yang digunakan dalam penelitian adalah metode analitik. Menurut Nazir (2014), metode analitik merupakan data dalam survei analitik dengan pengujian statistik. Tujuan dari metode analitik adalah untuk menguji hipotesis-hipotesis pada rumusan masalah yang ada. Metode analitik digunakan untuk menguji rumusan masalah pertama dan kedua. Rumusan masalah yang pertama yaitu mengenai kelayakan finansial agroindustri pengolahan sabut kelapa CV Sumber Sari, rumusan masalah kedua yaitu mengenai analisis sensitivitas agroindustri pengolahan sabut kelapa CV Sumber Sari.

Metode yang digunakan dalam penentuan sampel adalah Purposive Sampling yaitu teknik pengambilan yang digunakan berdasarkan sumber data yang dibutuhkan dengan pertimbangan tertentu. Pertimbangan yang dimaksud, antara lain orang tersebut dianggap paling mengerti tentang apa yang diharapkan oleh peneliti atau sebagai penguasa sehingga akan memudahkan peneliti untuk menjelajahi objek yang akan diteliti (Noor, 2014). Berdasarkan metode pengambilan contoh tersebut peneliti menentukan responden yaitu General Manager di agroindustri CV Sumber Sari dan mandor produksi dari kegiatan produksi pengolahan limbah sabut kelapa di agroindustri CV Sumber Sari Desa Lembengan Kecamatan Ledokombo Kabupaten Jember. Peneliti menentukan responden secara sengaja dengan memilih yang dianggap paling paham dan mengerti mengenai agroindustri tersebut dan mengetahui tujuan dari peneliti yang disebut dengan key informan.

Menurut Sujarweni (2014), teknik pengumpulan data merupakan cara yang dilakukan peneliti untuk mengungkap informasi dari responden sesuai lingkup penelitian. Selalu ada hubungan antara metode mengumpulkan data dengan masalah penelitian yang ingin dipecahkan. Metode pengumpulan data yang digunakan pada penelitian ini adalah observasi, studi dokumen, dan wawancara. Teknik observasi dilakukan untuk mengamati kegiatan produksi agroindustri pengolahan sabut kelapa CV Sumber Sari di Desa Lembengan Kecamatan Ledokombo Kabupaten Jember yang bertujuan untuk mendapatkan gambaran yang sesuai dengan permasalahan yang akan diteliti. Studi dokumentasi dalam penelitian ini adalah analisis mengenai kegiatan produksi agroindustri yang berkaitan dengan aliran keuangan sehingga mampu menganalisis kelayakan secara finansial dan analisis sensitivitas dari kegiatan agroindustri yang dilakukan. Wawancara dilakukan untuk memperoleh data primer pada penelitian mengenai aliran keuangan untuk melihat kelayakan secara finansial dan sensitivitas.

Untuk menguji rumusan masalah yang pertama mengenai kelayakan secara finansial adalah menggunakan kriteria penilaian investasi. Menurut Sucipto (2010) kriteria penilaian investasi terdiri dari Net Present Value (NPV), Internal Rate of Return (IRR), Payback Period (PP) dan Profitability 
Index (PI).Untuk menguji rumusan masalah yang kedua yaitu mengenai analisis sensitivitas pada agroindustri sabut kelapa CV Sumber Sari adalah dengan menggunakan metode analisis sensitivitas. Analisis ini berdasarkan pada kemungkinan yang paling optimis sampai pada kemungkinan yang paling pesimis. Range (jarak) antara kategori optimis dan pesimis yang lebih kecil merupakan investasi yang beresiko rendah. Analisis ini dilakukan untuk mengantisipasi adanya perubahan seperti :

1. Adanya cost over run, yaitu kenaikan biaya-biaya kontruksi, biaya bahan baku, dan produksi

2. Penurunan produktivitas.

3. Mundurnya jadwal pelaksanaan proyek

Analisis tersebut dapat diketahui seberapa jauh dampaknya terhadap kelayakan proyek. Pola pembiayaan yang terjadi yaitu pada skenario 1 dan skenario 2 . Skenario 1 adalah terjadinya peningkatan biaya operasional, sedangkan pada skenario 2 adalah terjadinya penurunan harga jual output.

\section{HASIL DAN PEMBAHASAN}

Berdasarkan Tabel 1 total penerimaan agroindustri sabut kelapa CV Sumber Sari diperoleh dari jumlah produksi dari produk yang di hasilkan dikalikan dengan harga jual dari kedua produk pada tahun tersebut. Total penerimaan agroindustri sabut kelapa CV Sumber Sari mengalami peningkatan setiap tahunnya, kecuali pada tahun 2018 karena pada tahun tersebut terjadi musibah kebakaran yang menyebabkan beberapa kerusakan baik dari bangunan, bahan baku, hasil produk, serta peralatan mesin. Total penerimaan penjualan cocopeat pada tahun 2018 sama seperti pada tahun sebelumnya, namun total penerimaan penjualan cocofiber lebih sedikit dari pada tahun sebelumnya sehingga total penerimaan pada tahun 2018 yaitu sebesar Rp 3.254.400.000.

Tabel 1. Total Penerimaan Agroindustri Sabut Kelapa CV Sumber Sari Kabupaten Jember

\begin{tabular}{ccccc}
\hline $\begin{array}{c}\text { Periode } \\
\text { Tahun ke }\end{array}$ & Tahun & $\begin{array}{c}\text { Penerimaan } \\
\text { Cocopeat (Serbuk } \\
\text { sabut) (Rp) }\end{array}$ & $\begin{array}{c}\text { Penerimaan } \\
\text { Cocofiber (Serat } \\
\text { Sabut) (Rp) }\end{array}$ & $\begin{array}{c}\text { Total Penerimaan } \\
\text { (Rp) }\end{array}$ \\
\hline 1 & 2011 & 129.600 .000 & 1.140 .048 .000 & 1.269 .648 .000 \\
2 & 2012 & 216.000 .000 & 1.753 .920 .000 & 1.969 .920 .000 \\
3 & 2013 & 259.200 .000 & 2.104 .704 .000 & 2.363 .904 .000 \\
4 & 2014 & 302.400 .000 & 2.455 .488 .000 & 2.757 .888 .000 \\
5 & 2015 & 432.000 .000 & 2.605 .824 .000 & 3.037 .824 .000 \\
6 & 2016 & 486.000 .000 & 3.551 .688 .000 & 4.037 .688 .000 \\
7 & 2017 & 513.000 .000 & 3.868 .020 .000 & 4.611 .600 .000 \\
8 & 2018 & 513.000 .000 & 2.578 .680 .000 & 3.254 .400 .000 \\
\hline
\end{tabular}

Sumber : Data Primer diolah Tahun 2019

Berdasarkan Tabel 2 total biaya investasi yang di keluarkan oleh agroindustri sabut kelapa CV Sumber Sari Kabupaten Jember sebesar Rp 1.191.100.000. Biaya investasi yang dikeluarkan terdiri dari dua bangunan, bangunan yang pertama untuk proses penggilingan bahan baku sabut kelapa dan bangunan yang kedua yaitu untuk proses pengepressan hasil olahan sabut kelapa yang siap untuk dijual. Biaya investasi lainnya untuk proses produksi adalah mesin penggiling dan mesin press. Biaya investasi yang dikeluarkan untuk mendukung jalannya produksi agroindustri sabut kelapa $\mathrm{CV}$ Sumber sari adalah alat transportasi berupa kendaraan truk yang berfungsi sebagai alat transportasi menjemput bahan baku dan proses perpindahan dalam kegiatan produksi, kemudian yang terakhir adalah sekop yang digunakan untuk memudahkan pekerjaan para pekerja dalam kegiatan produksi. 
Tabel 2 Biaya Investasi Agroindustri Sabut Kelapa CV Sumber Sari Kabupaten Jember

\begin{tabular}{rlcrrr}
\hline No & \multicolumn{1}{c}{ Uraian } & Satuan & Jumlah & $\begin{array}{c}\text { Harga Per Satuan } \\
(\mathbf{R p})\end{array}$ & \multicolumn{1}{c}{ Nilai (Rp) } \\
\hline 1 & Bangunan Penggilingan & Unit & 1 & 300.000 .000 & 300.000 .000 \\
2 & Bangunan Pengepressan & Unit & 1 & 400.000 .000 & 400.000 .000 \\
3 & Mesin Penggiling & Unit & 1 & 150.000 .000 & 150.000 .000 \\
4 & Mesin Press & Unit & 1 & 100.000 .000 & 100.000 .000 \\
5 & Kendaraan Truk & Unit & 4 & 60.000 .000 & 240.000 .000 \\
6 & Sekop & Unit & 10 & 110.000 & 1.100 .000 \\
\hline \multicolumn{2}{c}{ Total } & & & $\mathbf{1 . 1 9 1 . 1 0 0 . 0 0 0}$ \\
\hline
\end{tabular}

Sumber : Data Primer diolah Tahun 2019

Biaya operasional merupakan biaya yang dikeluarkan secara rutin pada periode tertentu. Biaya operasional terdiri dari biaya tetap dan baiya variabel. Biaya tetap merupakan biaya yang dikeluarkan dan tidak dipengaruhi oleh besarnya produk sabut kelapa yang dihasilkan. Berdasarkan Tabel 3 biaya tetap agroindustri sabut kelapa CV Sumber Sari Kabupaten Jember meliputi biaya perawatan. Biaya variabel merupakan biaya yang dipengaruhi oleh besarnya produk sabut kelapa yang dihasilkan. Berdasarkan Tabel 4 agroindustri sabut kelapa CV Sumber Sari Kabupaten Jember biaya variabel terdiri dari biaya bahan baku, biaya bahan bakar, dan biaya tenaga kerja.

Tabel 3. Biaya Tetap Agroindustri Sabut Kelapa CV Sumber Sari Kabupaten Jember

\begin{tabular}{|c|c|c|}
\hline No & Uraian & Nilai (Rp) \\
\hline 1 & Perawatan & 177.100 .000 \\
\hline & Total & 177.100 .000 \\
\hline
\end{tabular}

Sumber : Data Primer diolah Tahun 2019

Tabel 4. Biaya Variabel Agroindustri Sabut Kelapa CV Sumber Sari Kabupaten Jember

\begin{tabular}{llr}
\hline No & \multicolumn{1}{c}{ Uraian } & Nilai (Rp) \\
\hline 1 & Biaya Bahan Baku & 3.394 .880 .000 \\
2 & Biaya Bahan Bakar & 5.249 .280 .000 \\
3 & Biaya Tenaga Kerja & 3.284 .976 .000 \\
\hline & Total & $\mathbf{1 2 . 1 1 4 . 5 3 6 . 0 0 0}$ \\
\hline
\end{tabular}

Sumber : Data Primer diolah Tahun 2019

Aspek finansial merupakan suatu penilaian kelayakan usaha yang bertujuan untuk menganalisis apakah proyek yang direncanakan dapat memberikan manfaat atau justru proyek usaha tersebut hanya menghasilkan kerugian atau berada dalam titik impas. Aspek finansial yang dilakukan berupa perhitungan berapa jumlah modal atau biaya yang dibutuhkan untuk membangun dan mengoperasikan kegiatan usaha agroindustri sabut kelapa, serta jumlah penerimaan yang diterima dari usaha agroindustri sabut kelapa CV Sumber Sari. Berdasarkan Tabel 5 hasil perhitungan analisis kelayakan finansial agroindustri sabut kelapa CV Sumber Sari Kabupaten Jember yang dilihat dari kriteria kelayakan NPV dengan Discount Factor 6,50\% sebesar Rp Rp 6.794.149.777 artinya NPV lebih besar dari 0, Net B/C atau PI dengan Discount Factor 6,50\% sebesar 6,7041 artinya nilai tersebut lebih besar dari 1, IRR sebesar 66,32\% yang artinya IRR lebih besar dari Discount Rate Bank Indonesia sebesar 6,50\% dan PP sebesar 1 tahun 11 bulan 25 hari artinya lebih kecil dari umur ekonomis bisnis yaitu 5 tahun. Berdasarkan hasil tersebut agroindustri sabut kelapa CV Sumber Sari layak untuk diusahakan, karena dari semua nilai kriteria kelayakan yang di dapat tidak melebihi dari ukuran kriteria yang telah di tetapkan. 
Tabel 5. Kriteria Kelayakan Finansial Agroindustri Sabut Kelapa CV Sumber Sari Kabupaten Jember

\begin{tabular}{lllc}
\hline \multicolumn{1}{c}{ Kriteria } & \multicolumn{1}{c}{ Nilai } & \multicolumn{1}{c}{ Batasan } & Keterangan \\
\hline NPV ( DF 6,50\%) & Rp 6.794.149.777 & $>0$ & Layak \\
PI atau Net B/C (DF 6,50\%) & 6,7041 & $>1$ & Layak \\
IRR & $66,32 \%$ & $>6,50 \%$ & Layak \\
PP & 1 Tahun 11 Bulan 25 Hari & & Layak \\
\hline
\end{tabular}

Sumber : Data Primer diolah Tahun 2019

Perubahan parameter yang digunakan untuk mengetahui tingkat sensitivitas kelayakan finansial agroindustri sabut kelapa CV Sumber Sari Kabupaten Jember adalah biaya variabel bahan baku yang meningkat sebesar $100 \%$ dan penurunan harga jual sebesar $15 \%$ dengan parameter lainnya dianggap tetap. Perubahan parameter yang digunakan tersebut berdasarkan dengan keadaan yang pernah terjadi pada agroindustri CV Sumber Sari.

Tabel 6. Analisis Sensitivitas Agroindustri Sabut Kelapa CV Sumber Sari Kabupaten Jember pada Kenaikan Harga Variabel Bahan Baku 100\%

\begin{tabular}{lllc}
\hline \multicolumn{1}{c}{ Kriteria } & \multicolumn{1}{c}{ Nilai } & \multicolumn{1}{c}{ Batasan } & Keterangan \\
\hline NPV ( DF 6,50\%) & Rp 5.683.374.380 & $>0$ & Layak \\
PI atau Net B/C (DF 6,50\%) & 5,7715 & $>1$ & Layak \\
IRR & $56,14 \%$ & $>6,50 \%$ & Layak \\
PP & 2 Tahun 3 Bulan 27 Hari & & Layak \\
\hline
\end{tabular}

Sumber : Data Primer diolah Tahun 2019

Berdasarkan tabel 6 menunjukkan bahwa kelayakan finansial agroindustri sabut kelapa CV Sumber Sari Kabupaten Jember pada kenaikan biaya variabel bahan baku sabut kelapa sebesar $100 \%$ masih tetap layak. Hasil analisis sensitivitas menunjukkan nilai NPV masih lebih besar dari 0 yaitu Rp 5.683.374.380. Nilai PI atau Net B/C menurun yang pada awalnya 6,7041 menjadi 5,7715. Nilai IRR yaitu sebesar 56,14\% yang artinya lebih besar dari suku bunga Bank Indonesia yaitu sebesar $6,50 \%$. Nilai PP yang terjadi yaitu 2 tahun 3 bulan 27 hari yang artinya nilai PP agroindustri sabut kelapa CV Sumber Sari Kabupaten Jember tersebut masih lebih kecil dari umur ekonomis yaitu 5 tahun. Berdasarkan hasil analisis sensitivitas, batas toleransi kenaikan biaya variabel bahan baku adalah sebesar $612 \%$. Hasil analisis sensitivitas yang ditunjukkan dengan adanya kenaikan biaya variabel bahan baku sabut kelapa sebesar 100\% agroindustri sabut kelapa CV Sumber Sari Kabupaten Jember tetap layak untuk diusahakan, karena meskipun adanya perubahan tidak membuat agroindustri menjadi tidak layak sesuai dengan kriteria yang telah di tetapkan.

Tabel 7. Analisis Sensitivitas Agroindustri Sabut Kelapa CV Sumber Sari Kabupaten Jember pada Penurunan Harga Jual Produk Sebesar 15\%

\begin{tabular}{lllc}
\hline \multicolumn{1}{c}{ Kriteria } & \multicolumn{1}{c}{ Nilai } & \multicolumn{1}{c}{ Batasan } & Keterangan \\
\hline NPV ( DF 6,50\%) & Rp 4.042.239.653 & $>0$ & Layak \\
PI atau Net B/C (DF 6,50\%) & 4,3937 & $>1$ & Layak \\
IRR & $46,41 \%$ & $>6,50 \%$ & Layak \\
PP & 2 Tahun 7 Bulan 17 Hari & & Layak \\
\hline
\end{tabular}

Sumber : Data Primer diolah Tahun 2019

Berdasarkan tabel 7 menunjukkan bahwa kelayakan finansial agroindustri sabut kelapa CV Sumber Sari Kabupaten Jember pada penurunan harga jual produk sebesar 15\% masih tetap layak. Hasil analisis sensitivitas menunjukkan nilai NPV masih lebih besar dari 0 yaitu Rp 4.042.239.653. Nilai PI atau Net B/C menurun yang pada awalnya 6,7041 menjadi 4,3937. Nilai IRR yaitu sebesar $46,41 \%$ yang artinya lebih besar dari suku bunga Bank Indonesia yaitu sebesar 6,50\%. Nilai PP yang terjadi yaitu 2 tahun 7 bulan 17 hari yang artinya nilai PP agroindustri sabut kelapa CV Sumber Sari Kabupaten Jember tersebut masih lebih kecil dari umur ekonomis yaitu 5 tahun. Berdasarkan hasil analisis sensitivitas, batas toleransi penurunan harga jual produk olahan sabut kelapa adalah sebesar $40 \%$. Hasil analisis sensitivitas yang ditunjukkan dengan adanya penurunan harga jual produk sebesar 
15\% agroindustri sabut kelapa CV Sumber Sari Kabupaten Jember tetap layak untuk diusahakan, karena meskipun adanya perubahan tidak membuat agroindustri menjadi tidak layak sesuai dengan kriteria yang telah di tetapkan.

\section{KESIMPULAN}

Berdasarkan hasil perhitungan analisis kriteria kelayakan finansial agroindustri sabut kelapa CV Sumber Sari Kabupaten Jember selama 8 tahun (mulai tahun 2010 sampai 2018) secara finansial layak untuk di usahakan. Nilai yang di dapatkan yaitu NPV positif sebesar Rp 6.794.149.777,. Nilai PI atau Net B/C sebesar 6,7041. Nilai IRR sebesar 66,32\%. Jangka waktu pengembalian investasi yang diperlukan oleh agroindustri sabut kelapa CV Sumber Sari Kabupaten Jember adalah 1 tahun 11 bulan 25 hari (tingkat suku bunga Bank Indonesia 6,50\%). Hasil perhitungan analisis sensitivitas pada agroindustri sabut kelapa CV Sumber Sari Kabupaten Jember menunjukkan bahwa CV Sumber sari tidak sensitif terhadap perubahan kenaikan biaya variabel bahan baku sabut kelapa sebesar $100 \%$, karena nilai yang di hasilkan tidak melebihi batas kriteria pada analisis sensitivitas sehingga tetap layak untuk diusahakan. Ketika terjadi penurunan harga jual produk olahan sabut kelapa sebesar $15 \%$, agroindustri CV Sumber Sari Kabupaten Jember juga tidak sensitif terhadap perubahan tersebut sehingga tetap layak untuk di usahakan.

\section{DAFTAR PUSTAKA}

Mahmud, Z., dan Yulius, F. (2005). Prospek Pengolahan Hasil Samping Buah Kelapa Perspektif, $4(2), 55-63$.

Nazir, M. (2014). Metode Penelitian. Jakarta: PT. Ghalia Indonesia.

Noor, J. (2014). Metodologi Penelitian. Jakarta: Kencana Prenadamedia Group.

Ramadhan, D., Melya, R., dan Trio, S. (2018). Pemanfaatan Cocopeat sebagai Media Tumbuh Sengon Laut (Paraserianthes falcataria) dan Merbau Darat (Intsia palembanica). Sylva Lestari, 6(2), 22-31.

Sucipto, A. (2010). Studi Kelayakan Bisnis: Analisis Integratif dan Studi Kasus. Malang: Aditya Media.

Sugiyono. (2014). Metode Penelitian Kuantitatif Kualitatif dan R\&D. Bandung: Alfabeta.

Sujarweni, V.W. (2014). Metodologi Penelitian. Yogyakarta: Pustaka Baru Press.

Sukardi. (2011). Formulasi Definisi Agroindustri Dengan Pendekatan Backward Tracking Departemen Teknologi Industri Pertanian, Fateta Ipb Bogor.

Syarief, A. (1992). Operasionalisasi Pengembangan Agroindustri. 3 Oktober 1992. Seminar Nasional Sehari. 